\title{
Physiological Characteristics of Lactobacillus casei Strains and Their Alleviation Effects against Inflammatory Bowel Disease
}

\author{
Yang Liu ${ }^{1,2}$, Yifeng $\mathrm{Li}^{1,2}$, Xinjie Yu ${ }^{3}$, Leilei Yu ${ }^{1,2}$, Fengwei Tian ${ }^{1,2,4}$, Jianxin Zhao ${ }^{1,2}$, Hao Zhang ${ }^{1,25,6,7}$, \\ Qixiao Zhai ${ }^{1,2,4 *}$, and Wei Chen ${ }^{1,2,5,8}$ \\ ${ }^{1}$ State Key Laboratory of Food Science and Technology, Jiangnan University, Wuxi, Jiangsu 214122, P. R. China \\ ${ }^{2}$ School of Food Science and Technology, Jiangnan University, Wuxi, Jiangsu 214122, P.R. China \\ ${ }^{3}$ Hwa Chong Institution (College), 661 Bukit Timah Road, Singapore 269734, Singapore \\ ${ }^{4}$ International Joint Research Laboratory for Probiotics at Jiangnan University, Wuxi, Jiangsu 214122, P.R. China \\ ${ }^{5}$ National Engineering Research Center for Functional Food, Jiangnan University, Wuxi, Jiangsu 214122, P.R. China \\ ${ }^{6}$ Wuxi Translational Medicine Research Center and Jiangsu Translational Medicine Research Institute, Wuxi Branch, \\ P.R. China \\ ${ }^{7}$ (Yangzhou) Institute of Food Biotechnology, Jiangnan University, Yangzhou 225004, P.R. China \\ ${ }^{8}$ Beijing Innovation Center of Food Nutrition and Human Health, Beijing Technology and Business University \\ (BTBU), Beijing 100048, P.R. China
}

\begin{abstract}
Lactobacillus casei, one of the most widely used probiotics, has been reported to alleviate multiple diseases. However, the effects of this species on intestinal diseases are strain-specific. Here, we aimed to screen $L$. casei strains with inflammatory bowel disease (IBD)-alleviating effects based on in vitro physiological characteristics. Therefore, the physiological characteristics of 29 L. casei strains were determined, including gastrointestinal transit tolerance, oligosaccharide fermentation, HT-29 cell adhesion, generation time, exopolysaccharide production, acetic acid production, and conjugated linoleic acid synthesis. The effects of five candidate strains on mice with induced colitis were also evaluated. The results showed that among all tested $L$. casei strains, only Lactobacillus casei M2S01 effectively relieved colitis. This strain recovered body weight, restored disease activity index score, and promoted anti-inflammatory cytokine expression. Gut microbiota sequencing showed that $L$. casei M2S01 restored a healthy gut microbiome composition. The western blotting showed that the alleviating effects of $L$. casei M2S01 on IBD were related to the inhibition of the NFKB pathway. A good gastrointestinal tolerance ability may be one of the prerequisites for the IBDalleviating effects of $L$. casei. Our results verified the efficacy of $L$. casei in alleviating IBD and lay the foundation for the rapid screening of $L$. casei strain with IBD-alleviating effects.
\end{abstract}

Keywords: Lactobacillus casei, physiological characteristic, probiotic, inflammatory bowel disease, gut microbiota, NF-kB

\section{Introduction}

Inflammatory bowel disease (IBD) is an intestinal disease that mainly presents as Crohn's disease (CD) and ulcerative colitis (UC). Common clinical symptoms include diarrhea, abdominal pain, and bloody stools in severe cases. Although IBD has only emerged in the past 150 years, the incidence of IBD in many countries and regions is rising. Currently, IBD prevalence in partially developed countries exceeds $0.3 \%$ [1]. In the past 30 years, the incidence of IBD in South America has been rising. In the 1990s, Brazil had the fastest rate of increase, with a UC prevalence of $75 \%$ and a CD prevalence of $117 \%$ [2]. In Asia, the average annual incidence of IBD is 1.50 per 100,000 people. India and China have the highest incidences of IBD, at 9.31 and 3.64 per 100,000 people, respectively [3].

Probiotics are receiving attention as a potential treatment for IBD, and strains including Bacillus licheniformis [4], Bacteroides fragilis [5], Bifidobacterium longum [6], Lactococcus lactis [7], Lactobacillus plantarum [8], Lactobacillus reuteri [9] and many others have been shown to restore body weight, regulate the gut microbiome and restore intestinal barrier integrity in mouse models. This indicates the potential of probiotics to significantly 
prevent or inhibit the occurrence and development of IBD. In clinical trials, several strains of Lactobacillus and Bifidobacterium have shown therapeutic effects on IBD, including alleviation of intestinal mucosal inflammation, reduction of colonic myeloperoxidase, and fecal calprotectin levels, and increased time between symptom recurrences [10-13]. Lactobacillus casei (L. casei) is known to exert health-promoting functions and is widely found in functional foods. Several strains of $L$. casei, such as Shirota, BL23 and ATCC 393, have been reported to mitigate damage caused by intestinal diseases by improving disease activity index (DAI) score, restoring histopathological damage [14], inhibiting pro-inflammatory cytokine expression [15] and NF- $\kappa B$ signaling [16], and promoting the differentiation of Treg cells [17]. These findings indicate that $L$. casei strains have the potential to alleviate intestinal diseases. However, other studies have shown L. casei is limited in the treatment of intestinal diseases. Ingestion of $L$. casei did not inhibit the occurrence of diarrhea or prevent pathogenic infections [18, 19]. These conclusions suggest that the effects of $L$. casei on intestinal diseases are strain-specific.

Previous research has found that the beneficial effects of probiotics relate to their physiological characteristics. A strain's adhesion ability and its ability to tolerate gastrointestinal transit are directly related to its colonization of the gastrointestinal tract [20]. Effective fermentation of oligosaccharides can promote cell proliferation and resistance to intestinal injury [21]. Probiotic metabolites, such as exopolysaccharides (EPSs) and short-chain fatty acids (SCFAs), are also implicated in immune regulation [22], intestinal motility [23], intestinal mucosal barrier protection [24] and antagonization of pathogenic bacteria [25]. IBD-related studies also indicate that the physiological characteristics of probiotic strains may contribute to the alleviation of IBD: microencapsulation was found to significantly improve the gastrointestinal transit tolerance of Lactobacillus rhamnosus GG, and thus improved its colitis-alleviating effects [26]. Supplementation of Bacillus coagulans MTCC5856 with prebiotics was more effective than Bacillus coagulans MTCC5856 alone in the treatment of IBD [27]. The EPS and conjugated linoleic acid (CLA) produced by probiotics were also shown to restore intestinal mucosal barrier function and prevent colitis [28]. These studies indicate that the physiological characteristics of probiotics are related to their IBD-alleviating effects. However, previous studies only measured a single physiological characteristic to screen candidate strains from multiple species. Few studies have measured multiple physiological characteristics in a single species. It is still unknown what kind of physiological characteristics would contribute to the IBD-alleviating effects of $L$. casei strains.

Therefore, in this study, seven physiological characteristics of $L$. casei strains, including gastrointestinal transit tolerance, oligosaccharide utilization, HT-29 cell adhesion, generation time, EPS production, acetic acid production, and CLA synthesis were examined to screen several candidate strains with different typical physiological characteristics. Then the effects of candidate strains on IBD indicators, including body weight, DAI score, colon length restoration, gut microbiome regulation, anti-inflammatory factor expression, inhibition of NF- $\mathrm{KB}$ signaling and histopathological signs of recovery, were evaluated in mice, with the aim of finding $L$. casei strains with IBD-alleviating effects.

\section{Materials and Methods \\ Bacterial Strains and Culture}

All L. casei strains, including RS8-5, RS29-1, JS-WX-3-L-3, RS42-2, 5-1L, MJ1, NT52-4, NT72-1, HN13-1, 104S2, M2-03-F02-L4-1-5 (M25), M2-06-F01-L4-2-4, GD41-6, 34-3, 35-7, FJSSZ4-L2, F-FJND-D7-M5, VGZTR-132-M8, V-CQYB7-171-M7, V-CQYB6-170-M3 (VM3), F-JS-CZ-D2-L-3, FJSWX33-L3, V-CQRC7161-M2, M2-01-R02-S01 (M2S01), F-ZJHZ-D2-M1, V-CQQJ4-174-M3, V-CQQJ3-173-M1, V-CQYoY1-157M2 (VM2), and CCFM30, were provided by the Culture Collections of Food Microbiology, Jiangnan University (China) and cultured in MRS broth for $20 \mathrm{~h}$ at $37^{\circ} \mathrm{C}$

\section{Gastrointestinal Transit Tolerance Assay}

The gastrointestinal transit tolerance of $L$. case $i$ was measured according to the method of Maragkoudakis et al. [29]. Pepsin $(1: 10,000$, Sangon Biotech Ltd., China) was suspended in $0.5 \% \mathrm{w} / \mathrm{v}$ sterile saline at $3 \mathrm{~g} / \mathrm{l}$ and the $\mathrm{pH}$ adjusted to 3.0 to simulate gastric juices. In this simulated gastric juice, the bacterial incubation time was $180 \mathrm{~min}$. Trypsin (1:250, Sinopharm Chemical Reagent Ltd., China) and bile salt (LP0055, Thermo Fisher Scientific, UK) were dissolved in $0.5 \% \mathrm{w} / \mathrm{v}$ sterile saline at a concentration of $1 \mathrm{~g} / \mathrm{l}$ and $3 \mathrm{~g} / \mathrm{l}$, respectively, then adjusted to $\mathrm{pH} 8.0$ to simulate small intestinal juices. In the simulated small intestinal juices, the bacterial incubation time was $240 \mathrm{~min}$. The viable counts of $L$. casei were determined by plate counting at 0 and $420 \mathrm{~min}$ ( $180 \mathrm{~min}$ plus $240 \mathrm{~min}$ ). The gastrointestinal transit tolerance of $L$. casei strains was determined by comparing the number of viable cells at different time points.

\section{FOS and GOS Fermentation Assay}

The fructooligosaccharide (FOS) (95\% purity, Baolingbao Biology Ltd., Dezhou, China) and galactooligosaccharide (GOS) (95\% purity, Quantum Hi-Tech Ltd., China) fermentation ability of L. casei was measured according to the method of Kaplan and Hutkins [30], with modifications. Modified MRS agar was used as the experiment media. Briefly, 0.0075\% (w/v) bromocresol purple (Sinopharm Chemical Reagent Ltd.) and 0.3\% FOS (or GOS) were added to the MRS medium, which did not contain glucose or meat extract. The $\mathrm{pH}$ was adjusted to 7.2. MRS medium without glucose, meat extract, or FOS/GOS was used as the control. Each cultivated strain was diluted and spread on experimental media plates and control media plates and incubated for $12 \mathrm{~h}$ at $37^{\circ} \mathrm{C}$. The FOS and GOS fermentation abilities of $L$. casei strains were determined by whether or not a yellow zone surrounding the colonies appeared. 


\section{Adhesion Ability Assay}

The adhesion ability of $L$. case $i$ was measured according to the method of Walsham et al. [31], with modifications. Briefly, HT-29 cells were cultured in RPMI 1640 media (Thermo Fisher Scientific Co.) supplemented with 10\% heat-inactivated fetal bovine serum (Thermo Fisher Scientific Co.) and $20 \mathrm{mg} / \mathrm{ml}$ of streptomycin and penicillin (Bio-Light Biotechnology Ltd., China). The culture conditions for the cells were $37^{\circ} \mathrm{C}$ and a $5 \% \mathrm{CO}_{2}$ atmosphere. Cells were seeded on 6 -well plates at a density of $1 \times 10^{5} \mathrm{cells} / \mathrm{ml}$ and cultivated for $12 \mathrm{~h}$. Bacteria were harvested by centrifugation $\left(8,000 \times g, 4^{\circ} \mathrm{C}, 5 \mathrm{~min}\right)$ and washed twice with sterile PBS. The cells were inoculated with a final concentration of $5 \times 10^{7} \mathrm{CFU} / \mathrm{ml}$ in RPMI 1640 medium. After $120 \mathrm{~min}$ incubation, the cells were washed three times with sterile PBS. Six-well tissue culture plates were examined under a microscope (BA410E microscope, Motic China Group Ltd., China), and the number of bacteria adhering to 100 cells were counted. The adhesion ability of $L$. casei was expressed as bacteria per cell.

\section{Generation Time Assay}

The generation time of $L$. casei was measured according to the method of Shi et al. [32]. To determine generation time, all L. casei strains were cultured for $600 \mathrm{~min}$. The $600 \mathrm{~nm}$ optical density of the bacterial culture medium was recorded every 120 min using a Multiskan GO microplate reader (Thermo Fisher Scientific Co.). The generation time $(G)$ was calculated by:

$$
\begin{aligned}
& P_{t}=\mathrm{P}_{0} \times 2^{n} \\
& n=\log P_{t}-\log \mathrm{P}_{0} / \log 2 \\
& G=t / n
\end{aligned}
$$

$\mathrm{P}_{0}$ and $P_{\mathrm{t}}$ indicate the initial concentration of bacteria and the concentration at the end of the selected period, $t$ represents time and $n$ represents the number of generations.

\section{EPS Production Assay}

The EPS production ability of $L$. casei was measured according to the method of Tallon et al. [33]. EPSs produced by $L$. casei strains were quantified using the phenol/sulfuric acid method. Glucose was used to generate a standard curve. The results were expressed in $\mathrm{mg}$ (glucose)/g (dry cell weight).

\section{Acetic Acid Production Assay}

Bacterial culture medium $(0.5 \mathrm{ml})$ was acidified using sulfuric acid $(10 \%)$, and $0.8 \mathrm{ml}$ ether was added to the solution to extract acetic acid. The acetic acid production of $L$. case $i$ was measured by GC-MS, and the conditions for GC-MS referred to Wang et al. [34].

\section{CLA Synthesis Ability Assay}

The CLA synthesis ability of $L$. case $i$ was measured per the method of Yang et al. [35]. All strains were cultured in MRS broth containing linoleic acid $(0.5 \mathrm{mg} / \mathrm{ml})$ in an anaerobic environment for $72 \mathrm{~h}$. After $72 \mathrm{~h}$, the supernatant was separated by centrifugation $\left(5,000 \times g, 4^{\circ} \mathrm{C}, 10 \mathrm{~min}\right)$, and CLA was extracted by adding normal hexane, followed by a methylation process. The conversion rate of CLA were measured by GC-MS.

\section{Animal Experiment Design}

Adult male SPF C57BL/6 mice weighing 26-28 g (10 weeks, Shanghai Laboratory Animal Center, China) were housed in a $12 \mathrm{~h} \mathrm{light/dark} \mathrm{cycle} \mathrm{environment} \mathrm{under} \mathrm{controlled} \mathrm{temperature}\left(22-24^{\circ} \mathrm{C}\right)$ and humidity $(40-70 \%)$. The mice were fed standard commercial mouse food and distilled water. All animal experiments were approved by the Ethics Committee of Jiangnan University, China (JN.No20171115c2401220[73]) and were carried out under the guidelines set by the European Community (Directive 2010/63/EU).

Seventy mice were randomly assigned to stainless steel cages with 5 animals per cage (two cages per group) and were acclimatized for one week before the experiment. With the exception of the control group, groups were given $3.5 \%(\mathrm{w} / \mathrm{v})$ dextran sulfate sodium (DSS, $36-50 \mathrm{kDa}$, MP Biomedicals Ltd., USA) in drinking water for 7 consecutive days to induce colitis. During this period, control group and DSS group mice were administered sterile PBS $(0.2 \mathrm{ml} / \mathrm{mouse} /$ day $)$ whereas other groups were administered L. casei $\left(1 \times 10^{9} \mathrm{CFU} / 0.2 \mathrm{ml} / \mathrm{mouse} /\right.$ day $)$ strain suspension by gavage, as follows:

(1) Control group: Distilled water + sterile PBS for 7 days.

(2) DSS group: DSS + sterile PBS for 7 days.

(3) L. casei group 1: DSS + L. casei M25 bacterial suspension for 7 days.

(4) L. casei group 2: DSS + L. casei VM3 bacterial suspension for 7 days.

(5) L. casei group 3: DSS + L. casei M2S01 bacterial suspension for 7 days.

(6) L. casei group 4: DSS + L. casei VM2 bacterial suspension for 7 days.

(7) L. casei group 5: DSS + L. casei CCFM30 bacterial suspension for 7 days.

During the experiment, the body weight, stool characteristics, presence of blood in stool and DAI score were monitored and calculated daily. The DAI score was calculated by the formula:

$\mathrm{DAI}=($ body weight loss index + stool consistency index + stool blood content index $) / 3$.

Body weight loss index: body weight loss $<1 \%, 0$ points; $<5 \%, 1$ point; $<10 \%, 2$ points; $>15 \%, 4$ points. 
Stool consistency index: normal, 0 points; loose, 2 points; diarrhea, 4 points.

Stool blood content index: no occult blood, 0 points; occult blood, 2 points; clearly visible blood, 4 points.

After 7 days of gavage, fresh stool samples were collected and stored at $-80^{\circ} \mathrm{C}$. The mice were sacrificed. Their colons were separated and measured. Portions of colon were fixed with paraformaldehyde while the remainder was stored at $-80^{\circ} \mathrm{C}$.

\section{Histological Evaluation}

Colon samples were dehydrated in ethanol, followed by sectioning $(5 \mu \mathrm{m})$ and paraffin embedding, before staining with hematoxylin and eosin. The histological damage to the colon was examined with a microscope (BA410E microscope, Motic China Group Ltd.) and evaluated based on the colonic epithelium injury, villi injury, inflammatory cell infiltration degree, and edema degree. The scoring criteria are: no obvious symptoms, 0 points; moderate symptoms, 0.5 points; severe symptoms, 1 points. The histopathology score is the sum of the sub-scores.

\section{Biochemical Analysis of Colon}

Colon samples $(0.10 \mathrm{~g})$ were homogenized in ice-cold PBS ( $\mathrm{pH} 7.4)$, then centrifuged $\left(3,000 \times g, 4^{\circ} \mathrm{C}, 5 \mathrm{~min}\right)$. The IL-10 and IL-22 levels in the colon were measured with assay kits (SenBeiJia Biological Technology Ltd., China).

\section{Fecal DNA Extraction and Illumina Miseq Sequencing}

Fecal bacterial DNA was extracted using a FastDNA Spin Kit (MP Biomedicals Ltd.) according to the manufacturer's instructions. PCR and sequencing of gut microbiota composition were performed according to the method described by Wang et al. [36]. The forward primer sequence and the reverse primer sequence of the V3-V4 region were 5'-CCTAYGGGRBGCASCAG-3' and 5'-GGACTACNNGGGTA-3'. The QIIME 2 was used to analyze the data. Operational taxonomic units (OTUs) were chosen to $97 \%$ identity against the silva database (v 13_8). With a minimum number of 7706 reads, the sequences of each sample were randomly read to normalize the data, which were used in the diversity analyses. Principal component analysis (PCA) analysis was conducted with STAMP software, and LEfSe analysis was used to analyze differences in gut microbiota composition.

\section{Western Blotting Analysis}

Colon samples were lysed in radio immunoprecipitation assay lysis buffer (P0013K, without inhibitors, Beyotime Biotechnology Ltd., China) containing protease and phosphatase inhibitor mixtures $(50 \times$, Beyotime Biotechnology Ltd.), then centrifuged $\left(14,000 \times g, 4^{\circ} \mathrm{C}, 15 \mathrm{~min}\right)$ to collect the supernatant. The total concentration of protein was measured using a BCA protein assay kit (Beyotime Biotechnology Ltd.). Equal amounts of protein were separated using $8 \%$ SDS-PAGE and subsequently transferred to PVDF membranes, followed by a blocking process (60 min, room temperature). Five percent BSA (w/v) in Tris-buffered saline Tween $20(0.1 \%$, v/v) was used for blocking. The membrane was incubated with antibodies against NF- $\kappa B-p 65$ (ab16502, 1:2000, Abcam Ltd., USA), p-p65 (ab86299, 1:2000, Abcam Ltd.) and $\beta$-actin (1:1000, Santa Cruz Biotechnology Co., USA) at $4^{\circ} \mathrm{C}$ for $16 \mathrm{~h}$. The membrane was washed and incubated with corresponding secondary antibodies (A00098 and A00160, GenScript Biotechnology Ltd., China) for $60 \mathrm{~min}$ at room temperature. Following incubation, the membrane was washed and visualized using ECL western blotting detection reagent (ProteinSimple Co., USA). Alpha View Fluorchem Fc3 software (ProteinSimple Co.) was used to analyze the bands.

\section{Statistical Analysis}

All data are expressed as mean \pm standard error of the mean (SEM). One-way analysis of variance (ANOVA) was used to analyze the results, followed by Tukey's multiple comparison test to determine statistical significance. $p$-values less than or equal to 0.05 were considered to be statistically significant.

\section{Results}

\section{Gastrointestinal Transit Tolerance of $L$. casei Strains}

The survival rate of $29 \mathrm{~L}$. casei strains following exposure to simulated gastric juices and simulated small intestinal juices fluctuated between $72 \%$ and $95 \%$ (Fig. 1). Strains with a survival rate higher than $85 \%$ or less than $75 \%$ were selected for GOS and FOS fermentation testing.

\section{GOS and FOS Fermentation by L casei Strains}

Table 1 shows the FOS and GOS utilization of $10 \mathrm{~L}$. casei strains. The results indicate that FOS can be utilized by more strains than GOS. Two strains, VM2 and CCFM30, could ferment both kinds of oligosaccharides. M25, M3, and M2S01 could not ferment either oligosaccharide. Strains that could ferment both FOS and GOS or could not ferment either oligosaccharide were selected to test HT-29 cell adhesion, generation time, EPS production, acetic acid production, and CLA synthesis.

\section{Adhesion Ability of L. casei Strains}

The adhesion ability of the different $L$. casei strains exhibited a polarization trend (Fig. 2, $p<0.05$ ); the adhesion of two strains, M25 and VM2, exceeded 30 bacteria per cell, while VM3 exhibited the lowest adhesion with only 0.35 bacteria present per cell. 


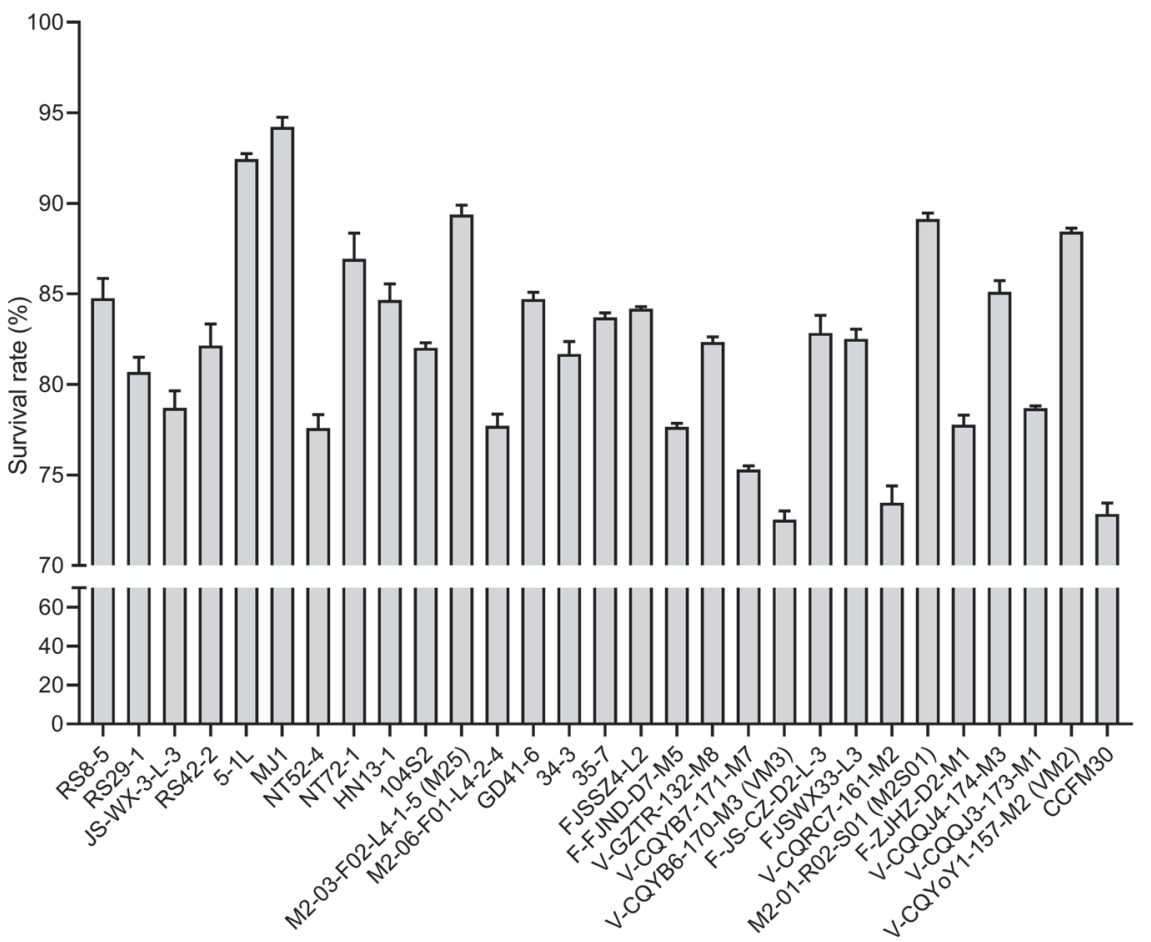

Fig. 1. The survival rate of Lactobacillus casei strains following in vitro simulated gastrointestinal transit. The viable counts of $L$. casei strains were determined by plate counting at 0 and $7 \mathrm{~h}$. The specific values of viable bacteria at the two time-points represent the gastrointestinal transit tolerance.

Table 1. FOS and GOS utilization by Lactobacillus casei strains.

\begin{tabular}{lcc}
\hline \multicolumn{1}{c}{ Strain } & FOS & GOS \\
\hline 5-1L & + & $/$ \\
MJ1 & + & $/$ \\
NT72-1 & + & $/$ \\
M25 & $/$ & $/$ \\
VM3 & $/$ & + \\
V-CQRC7-161-M2 & $/$ & $/$ \\
M2S01 & $/$ & $/$ \\
V-CQQJ4-174-M3 & + & + \\
VM2 & + & + \\
CCFM30 & + & + \\
\hline
\end{tabular}

+ Indicates FOS/GOS was fermented by this strain. / Indicates FOS/GOS was not fermented by this strain. FOS, fructooligosaccharides; GOS, galactooligosaccharides.

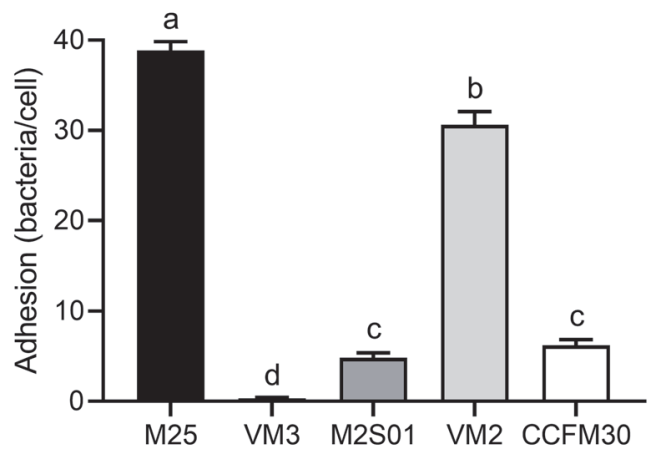

Fig. 2. The average number of bacteria adhered to 100 cells counted by a microscope. Letters a to $d$ indicate statistically significant differences $(p<0.05)$. 

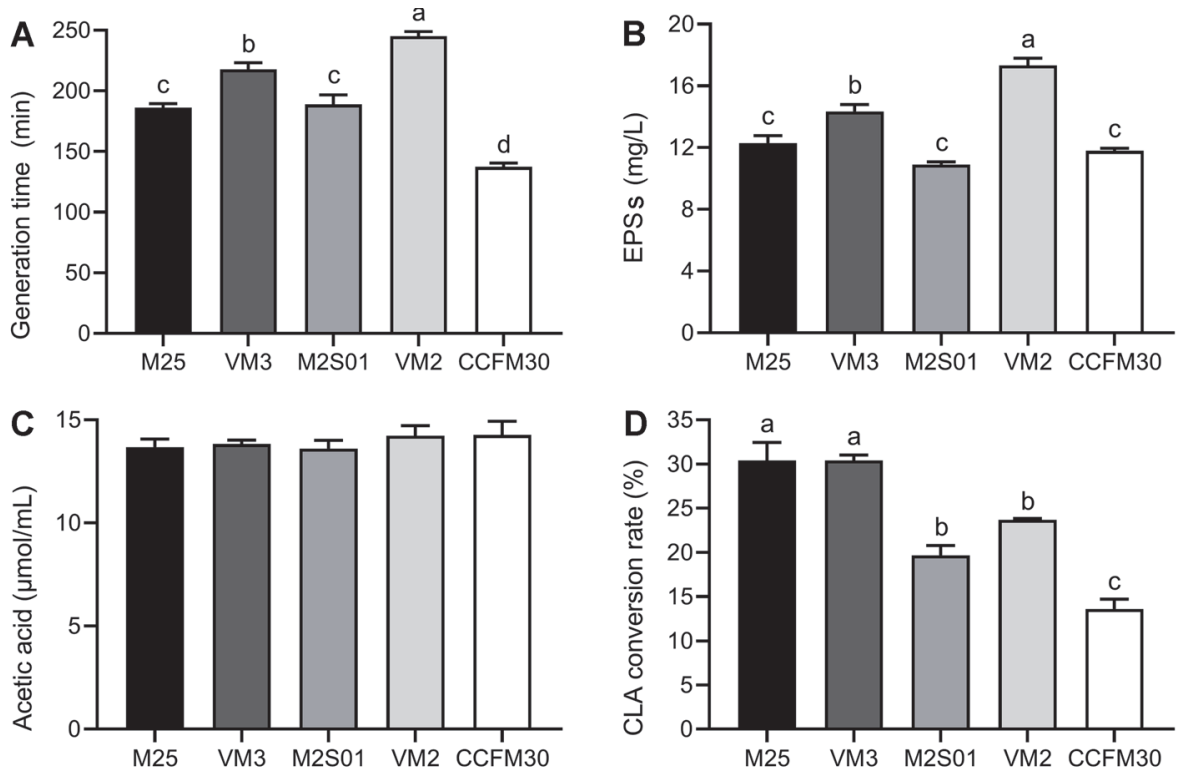

Fig. 3. Generation time, EPS production, acetic acid production, and CLA conversion rate of Lactobacillus casei strains. (A) The ratio of time to the number of generations in the logarithmic period of the strain; (B) EPSs of L. casei strains quantified by phenol/sulfuric acid method; (C) Acetic acid produced by L. casei measured by gas chromatography-mass spectrometry; (D) The CLA conversion rate of $L$. casei measured by GC-MS. EPSs: exopolysaccharides; CLA: conjugated linoleic acid. Letters a to $d$ indicate statistically significant differences $(p<0.05)$.

The Generation Time, EPS Production, Acetic Acid Production, and CLA Synthesis of L. casei Strains

The generation time of the strains varied greatly, ranging from $130 \mathrm{~min}$ to $250 \mathrm{~min}$ (Fig. 3A). The fastest growing strain was CCFM30, with a generation time of 137.4 mins. VM2 was the slowest growing strain, with a generation time of $245.2 \mathrm{~min}$. As shown in Fig. 3B, VM2 had the highest EPS production $(p<0.05)$, reaching
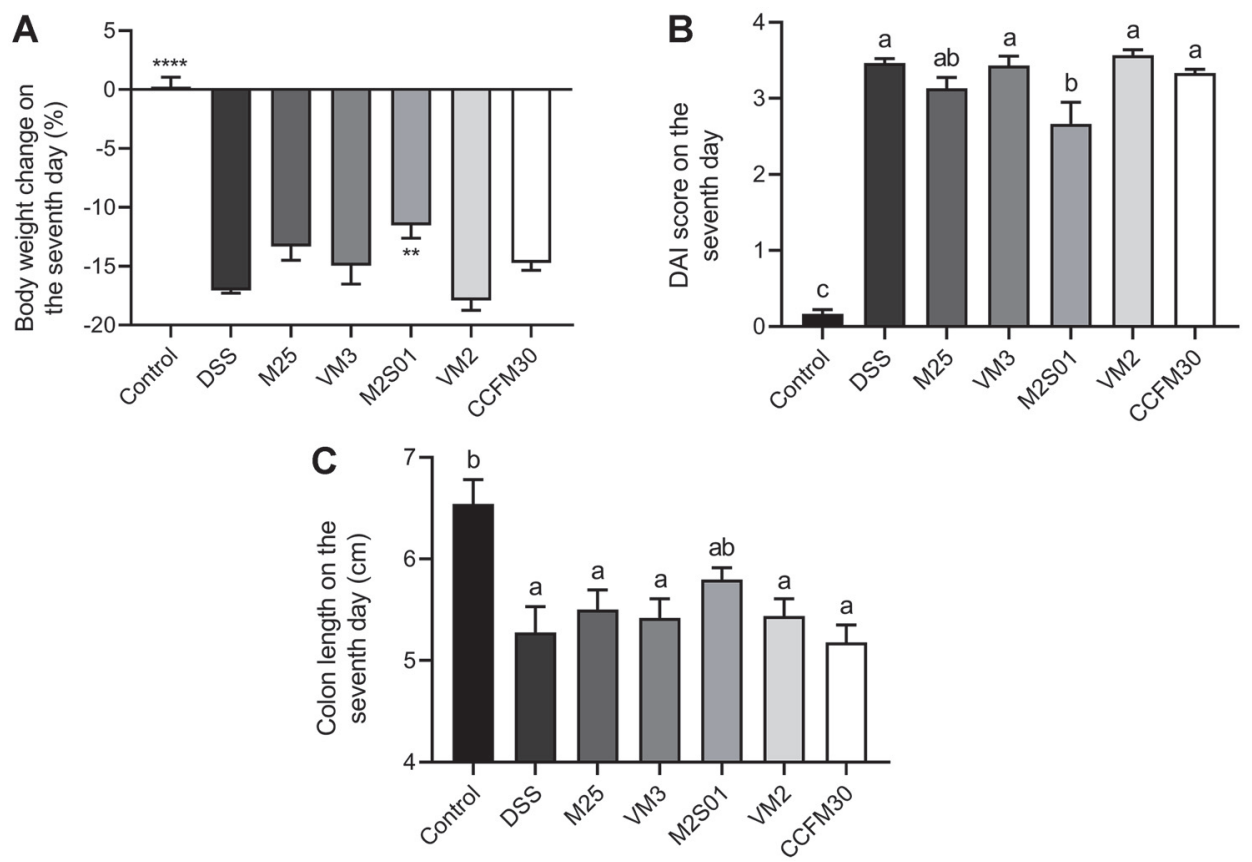

Fig. 4. The effect of Lactobacillus casei strains on a DSS-induced colitis mouse model. (A) The percentage of weight loss after seven days of DSS intake (\%); (B) DAI score after seven days of DSS intake. DAI score was calculated by the formula DAI = (body weight loss index + stool consistency index + stool blood content index $) / 3$; (C) Colon length after seven days of DSS intake. ${ }^{* *} p<0.01$ vs DSS group, ${ }^{* * *} p<0.0001$ vs DSS group. Letters a, b and c indicate statistically significant differences $(p<0.05)$. DSS: dextran sulfate sodium; DAI: disease activity index. 
$17.33 \mathrm{~g} / \mathrm{l}$. The lowest EPS producer was M2S01, producing $10.92 \mathrm{~g} / \mathrm{l}$. The EPS production of M25 and CCFM30 was slightly higher than M2S01. The EPS production of VM3 was lower than that of VM2 but higher than the other three strains $(p<0.05)$. The acetic acid production of all strains was approximately $400 \mu \mathrm{mol} / \mathrm{ml}$. Quantifying the CLA conversion rate of each $L$. casei strain using GC-MS revealed that the abilities of different L. casei strains to synthesize CLA were significantly different (Fig. 3D, $p<0.05$ ). Conversion rates ranged from $30 \%$ to $13 \%$

\section{Body Weight, DAI Score and Colon Length in Colitis-Induced Mice}

The ingestion of DSS resulted in a significant drop in body weight, a rapid shortening in colon length and an increase in DAI (Figs. 4A-4C). Seven days post-induction, compared to the control group, these three variables showed significant changes in the DSS group $(p<0.05)$. Following oral administration of five different $L$. casei strains, only M2S01 attenuated body weight loss, increased colon length and recovered the DAI score $(p<0.05)$. These findings indicate that the M2S01 strain can more effectively prevent colitis-induced damage compared to other strains.

A

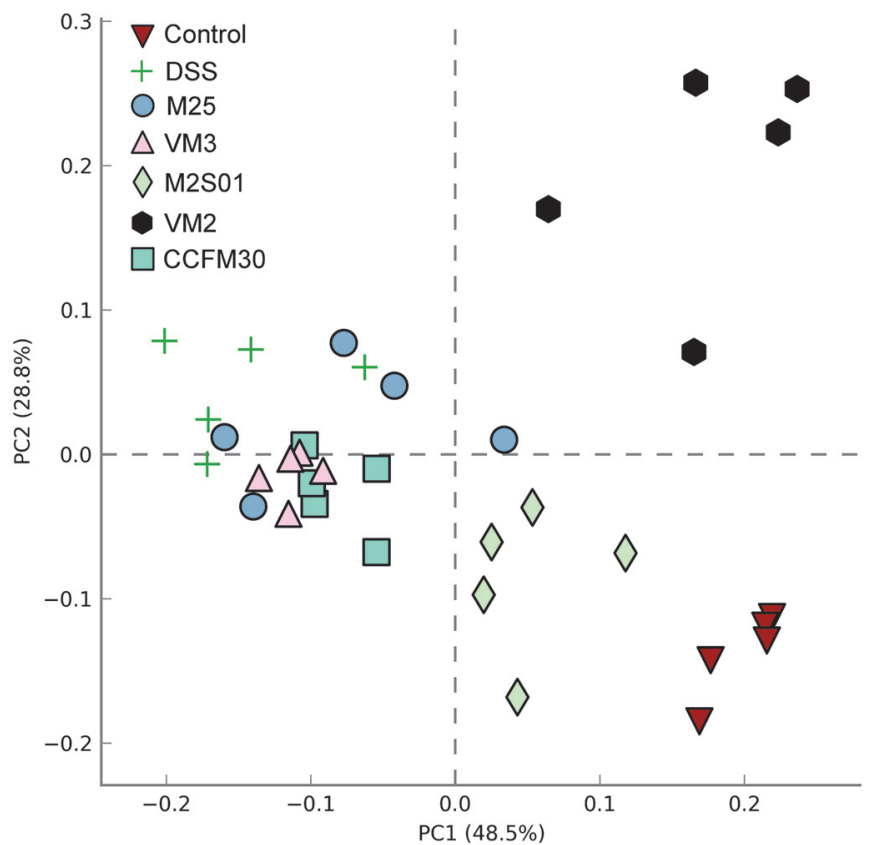

C

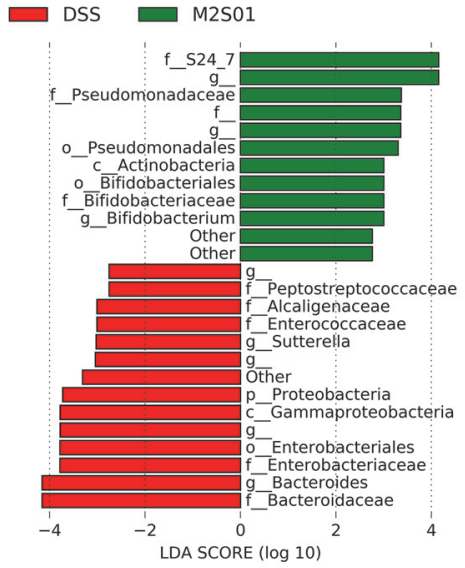

B

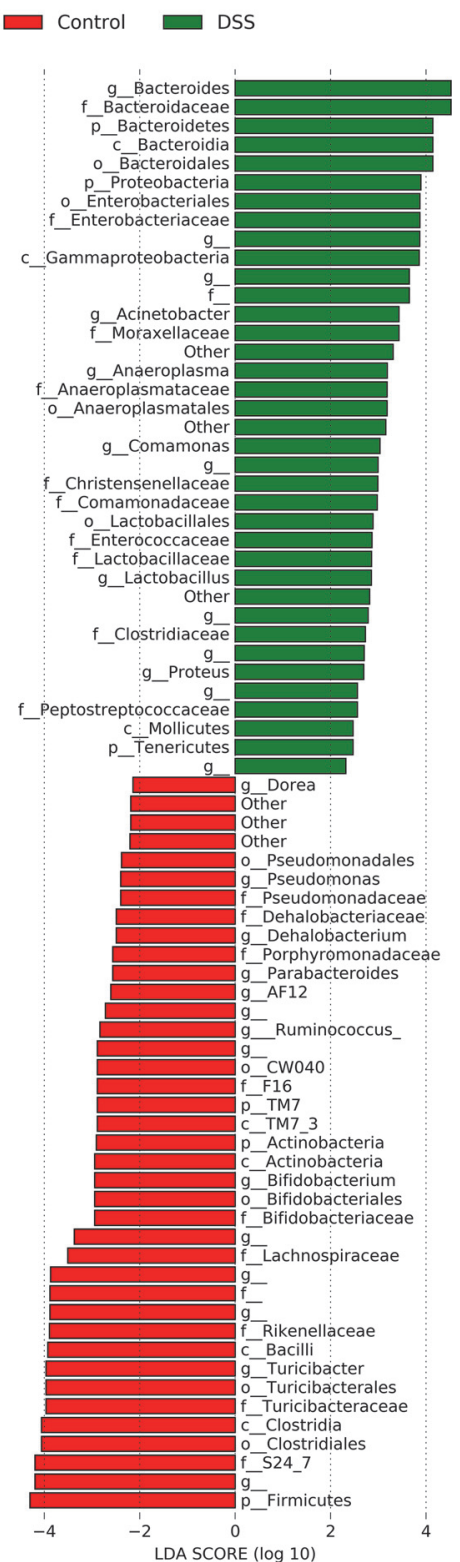

Fig. 5. Gut microbiota composition in colitis-induced mice. (A) Principal component analysis of mouse gut microbiota; (B) LEfSe analysis of control group and DSS group; (C) LEfSe analysis of M2S01 group and DSS group. DSS: dextran sulfate sodium. 


\section{Composition of Gut Microbiota}

PCA analysis of gut microbiota composition in mice is shown in Fig. 5A. Following ingestion of DSS, the relative abundance of Bacteroides, Acinetobacter, Anaeroplasma, Comamonas, Lactobacillus, and Proteus increased significantly. Dorea, Pseudomonas, Dehalobacterium, Parabacteroides, Ruminococcus, Bifidobacterium, and Turicibacter decreased in abundance to varying degrees (Fig. 5B). Compared to the other four strains of $L$. casei, M2S01 had a superior effect on microbiota recovery, with an increase in Bifidobacterium and a decrease in Bacteroides (Fig. 5C). The species composition of the M2S01 group was closer to that of the control group than to that of the DSS group. Oral administration of $L$. casei M2S01 resulted in a more healthy gut microbiome.

\section{Anti-Inflammatory Cytokines and NF- $\mathrm{kB}$ Expression in the Colon}

The anti-inflammatory effects of five $L$. casei strains were evaluated by measuring the levels of antiinflammatory cytokines IL-10 and IL-22 (Figs. 6A and 6B). The levels of IL-10 and IL-22 in the colon of the DSS group were significantly increased due to the presence of DSS in the drinking water. Compared to the DSS group, the L. casei M2S01 group had higher levels of IL-10 and IL-22 $(p<0.05)$. No therapeutic effects were observed for the other four L. casei strains. As seen in Figs. 6C and 6F, no differences in the expression of p65 were observed between the experimental groups. However, the p-p65 expression in the DSS group was significantly higher than the control group (Figs. 6C and 6E). The supplementation of L. casei M2S01 reduced the phosphorylation levels of p65 dramatically, to levels similar to that of the control (Fig. 6D). These results indicate that treatment with the L. casei strain M2S01 could prevent intestinal inflammation, and L. casei M2S01 might be able to regulate the NF$\kappa \mathrm{B}$ pathway, thereby inhibiting inflammation.

\section{Histopathological Analysis of Colon Tissue}

Histopathological analysis fully demonstrated the potential anti-inflammatory effects of $L$. casei M2S 01 . In the DSS group, almost all intestinal villi were missing. Intestinal lamina propria and intestinal submucosal fibroblasts were severely proliferated, accompanied by increased inflammatory cell infiltration (Figs. 7A and 7B). Treatment with L. casei M2S01 significantly reduced these signs of damage. Intestinal integrity was also restored (Fig. 7C). Moreover, the histopathological score showed that the colon injury in M2S01 group was significantly lower than that in DSS group (Fig. 7D).

A

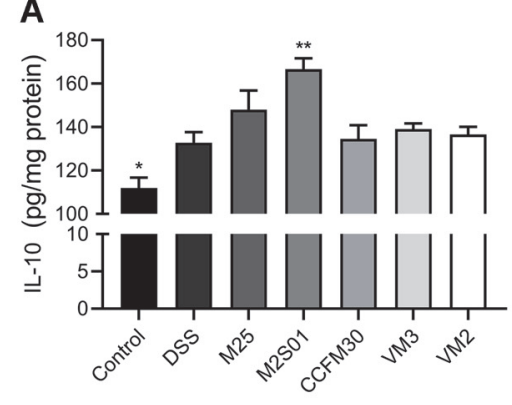

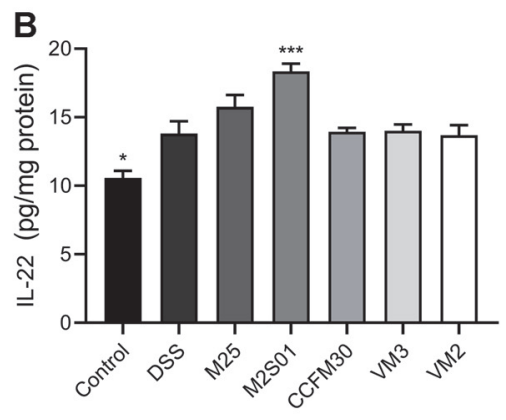

C

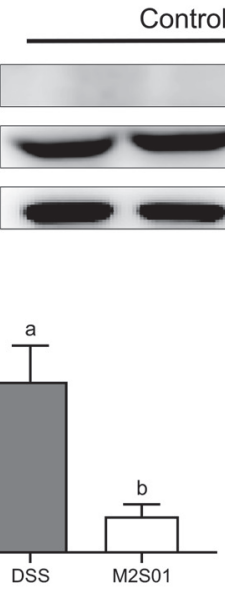

Control
DSS
M2S01

\section{$p-p 65$}

p65

$\beta$-actin
$\mathbf{E}$

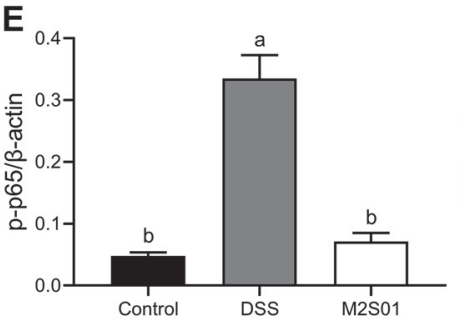

D

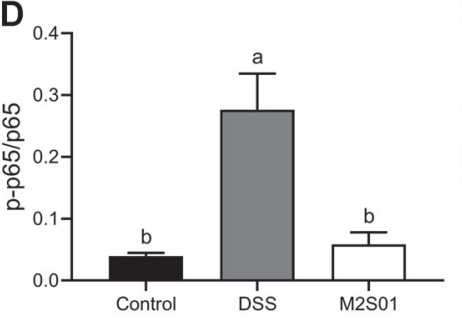

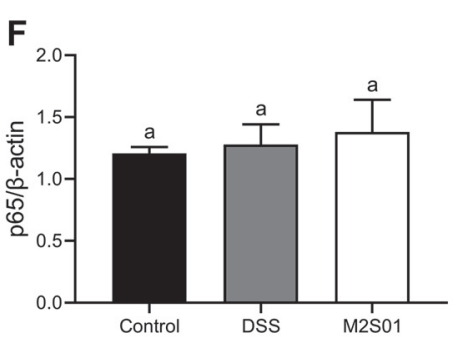

Fig. 6. The effects of Lactobacillus casei on the expression of anti-inflammatory cytokines and NF- $\mathrm{B}$ pathway in the colon. (A) The expression of IL-10 determined by the corresponding ELISA kits after seven days of DSS intake; (B) The expression of IL-22 determined by the corresponding ELISA kits after seven days of DSS intake; (C) The expression of p-p65 and p65 quantified by western blotting after seven days of DSS intake; (D) The relative gray value of p-p65 and p-65; (E) The relative gray value of p-p65 and $\beta$-actin; (F) The relative gray value of $\mathrm{p} 65$ and $\beta$-actin. ${ }^{*} p<0.05$ vs DSS group, ${ }^{* *} p<0.01$ vs DSS group, ${ }^{* * *} p<0.001$ vs DSS group. Letters a and $b$ indicate statistically significant differences $(p<0.05)$. DSS: dextran sulfate sodium. 
A

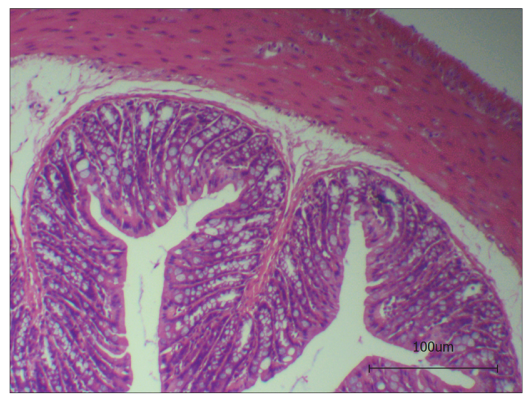

C

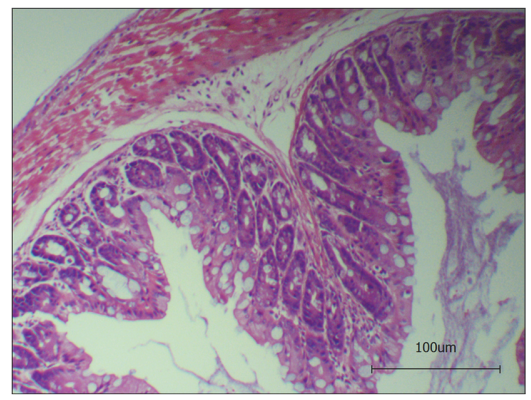

B

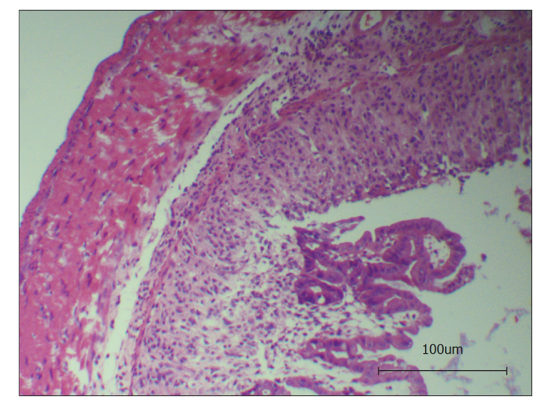

D

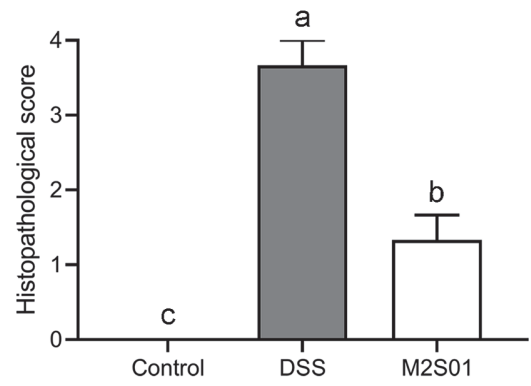

Fig. 7. Histopathological analysis of colon tissue. (A) Histopathological analysis of the control group without DSS intake; (B) Histopathological analysis of the DSS group after seven days of DSS intake; (C) Histopathological analysis of the M2S01 group after seven days of DSS intake (100x; scale bar = $100 \mu \mathrm{m})$; (D) Histopathological score of each group. DSS: dextran sulfate sodium.

\section{Discussion}

In this study, we aimed to find L.casei strains with IBD-alleviating effects based on physiological characteristics. Therefore, seven IBD-related physiological characteristics of $L$. casei strains, including gastrointestinal transit tolerance, oligosaccharide fermentation, HT-29 cell adhesion, generation time, EPS production, acetic acid production, and CLA synthesis, were investigated in vitro. Five L.casei strains with different physiological characteristics were screened. The effects of these strains on IBD in animal models were also evaluated. A bacterial strain's ability to survive gastrointestinal transit is necessary for colonization of the gut as well as for healthpromoting effects. During the process of colonization, the metabolic processes, cell structure and gene expression of Lactobacillus change [37]. A strong tolerance of gastrointestinal transit can aid the strain in adapting to the intestinal environment, achieving colonization of the gut and exerting a protective barrier function, thereby preventing the occurrence of IBD [18]. The metabolic activity of probiotics in the colon is directly related to their health-promoting effect. FOS and GOS are two widely used oligosaccharide prebiotics that are mostly digested in the colon and have the ability to regulate gut microbiota [38]. Research has shown that FOS and GOS can be metabolized by some Lactobacillus strains and that they promote the colonization process [39]. In this process, a series of small metabolites (such as SCFAs) are produced [40], and the proliferation of intestinal cells is promoted [21]. Thus, the oligosaccharide fermentation ability of strains can help maintain a stable gut environment and strengthen the epithelial barrier, which could contribute to the prevention of IBD. The adhesion ability of strains is a physiological characteristic also related to the IBD-alleviating functions of some strains. A high adhesion ability is advantageous in the intestinal colonization process and could prevent the damage caused by IBD and inhibit pathogenic bacteria adhesion [41]. During the process of adhering to intestinal cells, S-layer proteins react with host receptors to reduce the expression of TNF- $\alpha$ and IL-12 [42] and modulate signaling pathways within the host cells [43]. This is necessary for probiotics to regulate host immune responses and alleviate IBD. Generation time, an essential physiological characteristic of strains, is also a direct indication of the growth rate of a strain. Strains with a fast growth rate and a short generation time can compete for more nutrients in the gut microenvironment, which is beneficial in the relief of intestinal mucosal injury in IBD and resistance to pathogenic bacterial infections. Aside from stress resistance and growth ability, the ability of probiotics to produce beneficial substances, such as EPSs, acetic acid and CLA, is also related to IBD alleviation. EPSs are heterogeneous structures secreted by bacteria that help antagonize pathogenic bacteria [25], promoting the synthesis of SCFAs [44]. In the process of repairing IBD-induced inflammatory damage, EPSs can activate macrophages, promote the proliferation of T cells and inhibit TNF- $\alpha$ expression [45]. In the case of IBD-induced apoptosis, EPSs can regulate the expression of p53 and activate Caspase-3, thus killing tumor cells [46]. SCFAs are small molecules that play an essential role in human health. About $90 \%$ of SCFAs in the body are produced by colonic bacterial fermentation. Acetic acid is an SCFA. In vivo, acetic acid can be absorbed by intestinal epithelial cells to provide energy, strengthen gastrointestinal motility and protect the intestinal mucosal barrier [24], thus preventing pathological damage of the colon in IBD. In addition, adequate acetic acid supplementation can inhibit the proliferation of 
colorectal cancer cells and inhibit tumorigenesis [47]. CLA is a long-chain fatty acid found in humans and animals with many known health functions, such as anti-oxidation [48] and prevention of diabetes [49] and cardiovascular disease [50]. In addition, CLA can also regulate the body's immune response. Multiple reports indicate that CLA can reduce expression of TNF- $\alpha$ in the body, induce PPAR $\gamma$ receptor expression and inhibit the expression of NF- $\kappa B$, thereby alleviating IBD symptoms [51,52]. Therefore, all physiological characteristics of the strains, including stress resistance, growth ability and metabolic ability, are potentially related to their beneficial effects on IBD.

Based on these in vitro indicators, $L$. casei with different physiological characteristics was screened, and its efficacy in alleviating IBD was also evaluated. The results showed that the therapeutic effect of $L$. casei strains on IBD was strain-specific. In animal models, three indicators indicate the severity of IBD directly: body weight, DAI score and colon length. Moreover, most studies suggest that IBD may be related to an overreaction of the immune system to gut microbiota [53]. Therefore, the gut microbiome composition in each group was measured to explore whether each strain could alter the gut microbiome favorably. IL-10 is an anti-inflammatory cytokine that plays a vital role in controlling and preventing IBD. IL-10 is thought to block the metabolism of macrophages and promote impaired mitochondrial autophagy to reduce inflammation [54]. IL-22 is an anti-inflammatory cytokine of the IL-10 family that can induce the phosphorylation of STAT3 in intestinal epithelial cells, accelerate cell proliferation, and promote the recovery of the damaged intestinal mucosa [55]. NF- $\mathrm{KB}$ is a family of proteins with multi-directional regulatory functions and can regulate the expression of pro-inflammatory cytokines, immune receptors, and apoptosis-related proteins. p65 is a representative protein of the NF- $\mathrm{BB}$ pathway, with the phosphorylation level of $\mathrm{p} 65$ being directly related to activation of the signaling pathway [56]. However, the translocation of NF- $\kappa B$ to the nucleus and the DNA binding process of $\mathrm{p} 65$ could be inhibited by IL-10, thereby preventing tissue inflammation and apoptosis [57]. Therefore, the expression levels of IL-10, IL-22, and NF- $\mathrm{BB}$ in colon tissue were also determined in this study. The results demonstrate that only L. casei M2S01 had a therapeutic effect on IBD symptoms. It not only effectively relieved the weight loss and DAI increase in mice with colitis induced by DSS, but also favorably regulated the gut microbiome through increasing the relative abundance of Bifidobacterium and decreasing the relative abundance of Bacteroides. Furthermore, L. casei M2S01 promoted the expression of anti-inflammatory cytokines. Histological evaluation showed that supplementation with $L$. casei M2S01 alleviated colon tissue injury. Western blot results also showed that phosphorylation of p65 in the colon of the M2S01 group was significantly decreased, indicating that the activation of NF- $\mathrm{KB}$ was inhibited. This suggests that the beneficial physiological effects of $L$. casei M2S01 may be related to modulation of the NF- $\mathrm{BB}$ signaling pathway. Up to this point in this study, L. casei M2S01 had been screened as a probiotic strain with IBD-alleviating effects.

L. casei M2S01 showed excellent gastrointestinal transit tolerance, suggesting that this ability may be one of the prerequisites for the IBD-alleviating effects of L. casei. But L. casei M2S01 was not as good in terms of other physiological characteristics. In contrast, L. casei VM2, had good stress resistance, excellent growth and EPS synthesis ability, and was presumed capable of alleviating IBD. However, it did not show any therapeutic effect on IBD symptoms in this animal model. Not all L. casei strains with good gastrointestinal tolerance ability could alleviate IBD effectively.

There are three main internal factors that could lead to this mismatch. First, L. casei M2S01 might have some physiological characteristics or some metabolites that were not considered in this study but which participated in the process of alleviating IBD symptoms. Host-microbe interactions involve various microbial surface molecules and metabolites. Several studies have shown that bacterial surface proteins and secretory proteins have a preventive effect on inflammation. For example, the S-layer protein on the surface of Lactobacillus acidophilus can bind to the C-type lectin SIGNR3, regulating the gut microbiota and immune responses to protect the intestinal mucosal barrier, alleviating IBD [58]. p40 and p75, produced by Lactobacillus rhamnosus GG, can effectively regulate the activation of epidermal growth factor receptor (EGFR) and Akt, and also inhibit cytokine-induced epithelial cell apoptosis and the pathological damage of IBD [59]. Moreover, indole [60], bacteriocin [61] and other substances metabolized by some probiotic strains also have an inhibitory effect on pathogenic bacteria and could regulate the expression of pro-inflammatory factors like IL-8, reducing inflammation. Second, the synergistic effect of various physiological characteristics may also contribute to $L$. casei M2S01 having an IBDalleviating phenotype. Probiotics play a health-promoting role in vivo through complex processes in which several physiological attributes may be involved. Studies have shown that Lactobacillus-mediated inhibition of colon tumor cell proliferation is associated with Lactobacillus adhesion to the tumor cells and the subsequent production of butyric acid [62]. The inhibitory effect of L. plantarum on Salmonella in vivo may be related to its high gastrointestinal transit tolerance, adhesion ability and pathogen antagonism [63]. So, the alleviating effect of L. casei M2S01 on IBD may be attributable to the combined effects of various physiological characteristics. Finally, the environmental differences in vivo and in vitro may lead to different colonization, growth and metabolism of the strains. Compared with the in vivo environment, the in vitro environment is a relatively pure environmental condition. Therefore, the physiological characteristics of probiotics in vitro may be different from those in vivo. According to previous studies, the gastrointestinal transit tolerance of probiotic strains can be affected by the types of carbon sources in the growth environment [64], while CLA synthesis can be limited by the concentration of carbon sources [65]. However, the carbon sources in vitro and in vivo are often different. This may lead to some differences in the ability of the strains to alleviate IBD.

In summary, gastrointestinal transit tolerance ability may be one of the prerequisites for the IBD-alleviating effects but is not a decisive condition for these same effects.

The purpose of this study was to screen L. casei strains with IBD-alleviating effects based on the in vitro 
physiological characteristics. The results showed that L. casei M2S01 significantly restored the gut microbiota composition, activated the immune response, and alleviated the symptoms of IBD in a mouse model. A good gastrointestinal tolerance ability may be one of the prerequisites for the IBD-alleviating effects of $L$. casei. Our findings confirm the potential efficacy of $L$. casei for alleviating IBD and lay the foundation for the rapid screening of $L$. casei strain with IBD-alleviating effects.

\section{Acknowledgments}

This work was supported by the National Natural Science Foundation of China Program [No. 31530056, No. 31820103010 and No. 31871773]; the Natural Science Foundation of Jiangsu Province [BK20160175]; National First-Class Discipline Program of Food Science and Technology [JUFSTR20180102]; the BBSRC Newton Fund Joint Centre Award; and the Collaborative Innovation Centre of Food Safety and Quality Control in Jiangsu Province.

\section{Conflict of Interest}

The authors have no financial conflicts of interest to declare.

\section{References}

1. Ng SC, Shi HY, Hamidi N, Underwood FE, Tang W, Benchimol EI, et al. 2017. Worldwide incidence and prevalence of inflammatory bowel disease in the 21st century: a systematic review of population-based studies. Lancet 390: 2769-2778.

2. Eisenstein M. 2016. Biology: a slow-motion epidemic. Nature 540: S98-S99.

3. Ng SC, Kaplan GG, Tang W, Banerjee R, Adigopula B, Underwood FE, et al. 2018. Population density and risk of inflammatory bowel disease: A prospective population-based study in 13 countries or regions in Asia-Pacific. Am. J. Gastroenterol. 114: 107-115.

4. Li Y, Liu M, Zhou J, Hou B, Su X, Liu Z, et al. 2019. Bacillus licheniformis Zhengchangsheng" attenuates DSS-induced colitis and modulates the gut microbiota in mice. Benef. Microbes. 10: 543-553.

5. Deng H, Zhi F, Fan HY, Bai Y, Zhang Y, Zhang Z, et al. 2018. Bacteroides fragilis prevents Clostridium difficile infection in a mouse model by restoring gut barrier and microbiome regulation. Front. Microbiol. 9: 2976

6. Chen X, Fu Y, Wang L, Qian W, Zheng F, Hou X. 2019. Bifidobacterium longum and VSL\# $3^{\circ}$ amelioration of TNBS-induced colitis associated with reduced HMGB1 and epithelial barrier impairment. Dev. Comp. Immunol. 92: 77-86.

7. Song L, Xie W, Liu Z, Guo D, Zhao D, Qiao X, et al. 2019. Oral delivery of a Lactococcus lactis strain secreting bovine lactoferricinlactoferrampin alleviates the development of acute colitis in mice. Appl. Microbiol. Biotechnol. 103: 6169-6186.

8. Zhang F, Li Y, Wang X, Wang S, Bi D. 2019. The impact of Lactobacillus plantarum on the gut microbiota of mice with DSS-induced colitis. Biomed. Res. Int. 2019: 3921315.

9. Jang H-M, Lee K-E, Kim D-H. 2019. The preventive and curative effects of Lactobacillus reuteri NK33 and Bifidobacterium adolescentis NK98 on immobilization stress-induced anxiety/depression and colitis in mice. Nutrients 11: 819.

10. Oliva S, Di Nardo G, Ferrari F, Mallardo S, Rossi P, Patrizi G, et al. 2012. Randomised clinical trial: the effectiveness of Lactobacillus reuteri ATCC 55730 rectal enema in children with active distal ulcerative colitis. Aliment. Pharm. Ther. 35: 327-334.

11. Ishikawa H, Matsumoto S, Ohashi Y, Imaoka A, Setoyama H, Umesaki Y, et al. 2011. Beneficial effects of probiotic bifidobacterium and galacto-oligosaccharide in patients with ulcerative colitis: a randomized controlled study. Digestion 84: 128-133.

12. Furrie E, Macfarlane S, Kennedy A, Cummings J, Walsh S, O’neil D, et al. 2005. Synbiotic therapy (Bifidobacterium longum/Synergy 1) initiates resolution of inflammation in patients with active ulcerative colitis: a randomised controlled pilot trial. Gut 54:242-249.

13. Bjarnason I, Sission G. 2019. A randomised, double-blind, placebo-controlled trial of a multi-strain probiotic in patients with asymptomatic ulcerative colitis and Crohn's disease. Inflammopharmacology 27: 465-473.

14. Sgouras D, Maragkoudakis P, Petraki K, Martinez-Gonzalez B, Eriotou E, Michopoulos S, et al. 2004. In vitro and in vivo inhibition of Helicobacter pylori by Lactobacillus casei strain Shirota. Appl. Environ. Microbiol. 70: 518-526.

15. Xu C, Guo Y, Qiao L, Ma L, Cheng Y, Roman A. 2018. Biogenic synthesis of novel functionalized selenium nanoparticles by Lactobacillus casei ATCC 393 and its protective effects on intestinal barrier dysfunction caused by enterotoxigenic Escherichia coli K88. Front. Microbiol. 9: 1129.

16. Zakostelska Z, Kverka M, Klimesova K, Rossmann P, Mrazek J, Kopecny J, et al. 2011. Lysate of probiotic Lactobacillus casei DN-114 001 ameliorates colitis by strengthening the gut barrier function and changing the gut microenvironment. PLoS One 6: e27961.

17. Thakur BK, Saha P, Banik G, Saha DR, Grover S, Batish VK, et al. 2016. Live and heat-killed probiotic Lactobacillus casei Lbs2 protects from experimental colitis through Toll-like receptor 2-dependent induction of T-regulatory response. Int. Immunopharmacol. 36: 39-50.

18. Arena MP, Capozzi V, Spano G, Fiocco D. 2017. The potential of lactic acid bacteria to colonize biotic and abiotic surfaces and the investigation of their interactions and mechanisms. Appl. Microbiol. Biotechnol. 101, 2641-2657

19. Xie C, Li J, Wang K, Li Q, Chen D. 2015. Probiotics for the prevention of antibiotic-associated diarrhoea in older patients: a systematic review. Travel. Med. Infect. Dis. 13: 128-134.

20. Dunne C, O'Mahony L, Murphy L, Thornton G, Morrissey D, O'Halloran S, et al. 2001. In vitro selection criteria for probiotic bacteria of human origin: correlation with in vivo findings. Am. J. Clin. Nutr. 73: 386s-392s.

21. Winkler J, Butler R, Symonds E. 2007. Fructo-oligosaccharide reduces inflammation in a dextran sodium sulphate mouse model of colitis. Digest. Dis. Sci. 52: 52-58.

22. Hidalgo-Cantabrana C, López P, Gueimonde M, Clara G, Suárez A, Margolles A, et al. 2012. Immune modulation capability of exopolysaccharides synthesised by lactic acid bacteria and bifidobacteria. Probiotics. Antimicrob.Proteins 4: 227-237.

23. Kamath PS, Hoepfner M, Phillips S. 1987. Short-chain fatty acids stimulate motility of the canine ileum. Am. J. Physiol. 253: G427G433.

24. Feng Y, Wang Y, Wang P, Huang Y, Wang F. 2018. Short-chain fatty acids manifest stimulative and protective effects on intestinal barrier function through the inhibition of NLRP3 inflammasome and autophagy. Cell. Physiol. Biochem. 49: 190-205.

25. Jones SE, Paynich ML, Kearns DB, Knight KL. 2014. Protection from intestinal inflammation by bacterial exopolysaccharides. J. Immunol. 192: 4813-4820.

26. Li R, Zhang Y, Polk DB, Tomasula PM, Yan F, Liu L. 2016. Preserving viability of Lactobacillus rhamnosus GG in vitro and in vivo by a new encapsulation system. J. Control. Release 230: 79-87.

27. Shinde T, Perera AP, Vemuri R, Gondalia SV, Karpe AV, Beale DJ, et al. 2019. Synbiotic supplementation containing whole plant sugar cane fibre and probiotic spores potentiates protective synergistic effects in mouse model of IBD. Nutrients 11: 818 . 
28. Şengül N, Aslím B, Uçar G, Yücel N, Işık S, Bozkurt H, et al. 2006. Effects of exopolysaccharide-producing probiotic strains on experimental colitis in rats. Dis. Colon Rectum. 49: 250-258.

29. Maragkoudakis PA, Zoumpopoulou G, Miaris C, Kalantzopoulos G, Pot B, Tsakalidou E. 2006. Probiotic potential of Lactobacillus strains isolated from dairy products. Int. Dairy. J. 16: 189-199.

30. Kaplan H, Hutkins RW. 2000. Fermentation of fructooligosaccharides by lactic acid bacteria and bifidobacteria. Appl. Environ. Microbiol. 66: 2682-2684.

31. Walsham AD, MacKenzie DA, Cook V, Wemyss-Holden S, Hews CL, Juge N, et al. 2016. Lactobacillus reuteri inhibition of enteropathogenic Escherichia coli adherence to human intestinal epithelium. Front. Microbiol. 7: 244.

32. Shi Y, Zhao J, Kellingray L, Zhang H, Narbad A, Zhai Q, et al. 2019. 2019. In vitro and in vivo evaluation of Lactobacillus strains and comparative genomic analysis of Lactobacillus plantarum CGMCC12436 reveal candidates of colonise-related genes. Food Res. Int. 119: $813-821$.

33. Tallon R, Bressollier P, Urdaci MC. 2003. 2003. Isolation and characterization of two exopolysaccharides produced by Lactobacillus plantarum EP56. Res. Microbiol. 154: 705-712.

34. Wang L, Hu L, Xu Q, Jiang T, Fang S, Wang G, et al. 2017. Bifidobacteria exert species-specific effects on constipation in BALB/c mice. Food. Funct. 8: 3587-3600.

35. Yang B, Chen H, Gu Z, Tian F, Ross R, Stanton C, et al. 2014. Synthesis of conjugated linoleic acid by the linoleate isomerase complex in food-derived lactobacilli. J. Appl. Microbiol. 117: 430-439.

36. Wang L, Pan M, Li D, Yin Y, Jiang T, Fang S, et al. 2017. Metagenomic insights into the effects of oligosaccharides on the microbial composition of cecal contents in constipated mice. J. Funct. Foods 38: 486-496.

37. Marco ML, De Vries MC, Wels M, Molenaar D, Mangell P, Ahrne S, et al. 2010. Convergence in probiotic Lactobacillus gut-adaptive responses in humans and mice. ISME J. 4: 1481.

38. Wang L, Hu L, Yan S, Jiang T, Fang S, Wang G, et al. 2017. Effects of different oligosaccharides at various dosages on the composition of gut microbiota and short-chain fatty acids in mice with constipation. Food Funct. 8: 1966-1978.

39. McBain A, Macfarlane G. Modulation of genotoxic enzyme activities by non-digestible oligosaccharide metabolism in in-vitro human gut bacterial ecosystems. J. Med. Microbiol. 50: 833-842.

40. Peng X, Li S, Luo J, Wu X, Liu L. 2013. Effects of dietary fibers and their mixtures on short chain fatty acids and microbiota in mice guts. Food Funct. 4: 932-938.

41. Dutra V, Silva AC, Cabrita P, Peres C, Malcata X, Brito L. 2016. Lactobacillus plantarum LB95 impairs the virulence potential of Gram-positive and Gram-negative food-borne pathogens in HT-29 and Vero cell cultures. J. Med. Microbiol. 65: 28-35.

42. Rong J, Zheng H, Liu M, Hu X, Wang T, Zhang X, et al. 2015. Probiotic and anti-inflammatory attributes of an isolate Lactobacillus helveticus NS8 from Mongolian fermented koumiss. BMC Microbiol. 15: 196.

43. Yadav AK, Tyagi A, Kumar A, Panwar S, Grover S, Saklani AC, et al.2017. Adhesion of lactobacilli and their anti-infectivity potential. Crit. Rev. Food Sci. 57: 2042-2056.

44. Khan MA, Ma C, Knodler LA, Valdez Y, Rosenberger CM, Deng W, et al. 2006. Toll-like receptor 4 contributes to colitis development but not to host defense during Citrobacter rodentium infection in mice. Infect. Immun. 74: 2522-2536.

45. Wang J, Wu T, Fang X, Min W, Yang Z. 2018. Characterization and immunomodulatory activity of an exopolysaccharide produced by Lactobacillus plantarum JLK0142 isolated from fermented dairy tofu. Int. J. Biol. Macromol. 115: 985-993.

46. Ou Y, Xu S, Zhu D, Yang X. 2014. 2014. Molecular mechanisms of exopolysaccharide from Aphanothece halaphytica (EPSAH) induced apoptosis in HeLa cells. PLoS One 9: e87223.

47. Hague A, Elder DJ, Hicks DJ, Paraskeva C. 1995. Apoptosis in colorectal tumour cells: induction by the short chain fatty acids butyrate, propionate and acetate and by the bile salt deoxycholate. Int. J. Cancer 60: 400-406.

48. Ochoa JJ, Farquharson AJ, Grant I, Moffat L, Heys SD, Wahle KW. 2004. Conjugated linoleic acids (CLAs) decrease prostate cancer cell proliferation: different molecular mechanisms for cis-9, trans-11 and trans-10, cis-12 isomers. Carcinogenesis 25: $1185-1191$.

49. Malinska H, Hüttl M, Oliyarnyk O, Bratova M, Kazdova L. 2015. Conjugated linoleic acid reduces visceral and ectopic lipid accumulation and insulin resistance in chronic severe hypertriacylglycerolemia. Nutrition 31: 1045-1051.

50. Bruen R, Fitzsimons S, Belton O. 2017. Atheroprotective effects of conjugated linoleic acid. Br. J. Clin. Pharmacl. 83: 46-53.

51. Bassaganya-Riera J, Reynolds K, Martino-Catt S, Cui Y, Hennighausen L, Gonzalez F, et al. 2004. Activation of PPAR $\gamma$ and $\delta$ by conjugated linoleic acid mediates protection from experimental inflammatory bowel disease. Gastroenterology 127: 777-791.

52. Evans NP, Misyak SA, Schmelz EM, Guri AJ, Hontecillas R, Bassaganya-Riera J. 2010. Conjugated linoleic acid ameliorates inflammation-induced colorectal cancer in mice through activation of PPAR $\gamma$. J. Nutr. 140: 515-521.

53. Zhang M, Sun K, Wu Y, Yang Y, Tso P, Wu Z. 2017. Interactions between intestinal microbiota and host immune response in inflammatory bowel disease. Front. Immunl. 8: 942.

54. Ip WE, Hoshi N, Shouval DS, Snapper S, Medzhitov R. 2017. Anti-inflammatory effect of IL-10 mediated by metabolic reprogramming of macrophages. Science 356: 513-519.

55. Lindemans CA, Calafiore M, Mertelsmann AM, O'connor MH, Dudakov JA, Jenq RR, et al. 2015. Interleukin-22 promotes intestinal-stem-cell-mediated epithelial regeneration. Nature 528: 560-564.

56. Hoberg JE, Popko AE, Ramsey CS, Mayo MW. 2006. IkB kinase $\alpha$-mediated derepression of SMRT potentiates acetylation of RelA/ p65 by p300. Mol. Cell. Biol. 26: 457-471.

57. Al-Ashy R, Chakroun I, El-Sabban ME, Homaidan FR. 2006. The role of NF-kappaB in mediating the anti-inflammatory effects of IL-10 in intestinal epithelial cells. Cytokine 36: 1-8.

58. Lightfoot YL, Selle K, Yang T, Goh YJ, Sahay B, Zadeh M, et al. 2015. SIGNR3-dependent immune regulation by Lactobacillus acidophilus surface layer protein A in colitis. EMBO J. 34: 881-895.

59. Yoda K, Miyazawa K, Hosoda M, Hiramatsu M, Yan F, He F. 2014. Lactobacillus GG-fermented milk prevents DSS-induced colitis and regulates intestinal epithelial homeostasis through activation of epidermal growth factor receptor. Eur. J. Nutr. 53: 105-115.

60. Bansal T, Alaniz RC, Wood TK, Jayaraman A. 2010. The bacterial signal indole increases epithelial-cell tight-junction resistance and attenuates indicators of inflammation. Proc. Natl. Acad. Sci. USA 107: 228-233.

61. Corr SC, Li Y, Riedel CU, O'Toole PW, Hill C, Gahan CG. 2007. Bacteriocin production as a mechanism for the antiinfective activity of Lactobacillus salivarius UCC118. Proc. Natl. Acad. Sci. USA 104: 7617-7621.

62. Thirabunyanon M, Hongwittayakorn P. 2013. 2013. Potential probiotic lactic acid bacteria of human origin induce antiproliferation of colon cancer cells via synergic actions in adhesion to cancer cells and short-chain fatty acid bioproduction. Appl. Biochem. Biotechnol. 169: 511-525.

63. Feng J, Liu P, Yang X, Zhao X. 2015. Screening of immunomodulatory and adhesive Lactobacillus with antagonistic activities against Salmonella from fermented vegetables. World. J. Microb. Biotechnol. 31: 1947-1954.

64. Nagata Y, Hashiguchi K, Kamimura Y, Yoshida M, Gomyo T. 2009. The gastrointestinal transit tolerance of Lactobacillus plantarum strain No. 14 depended on the carbon source. Biosci. Biotechnol. Biochnol. 73: 2650-2655.

65. Peng M, Tabashpengsum Z, Patel P, Bernhardt C, Biswas D. 2018. Linoleic acids overproducing Lactobacillus casei limits growth, survival, and virulence of Salmonella Typhimurium and enterohaemorrhagic Escherichia coli. Front. Microbiol. 9: 2663. 